\title{
Redesigning Mobile Human-Resource Management in Small and Medium Enterprises
}

\author{
Daniel Hadrian Yohandy ${ }^{1 *}$, Parjanto ${ }^{2)}$, Flourensia Sapty Rahayu ${ }^{3)}$ \\ 1)2)3) Universitas Atma Jaya Yogyakarta \\ Jln. Babarsari no. 44, Yogyakarta, Indonesia \\ 1)nverbe@gmail.com \\ ${ }^{2)}$ parjanto_79@yahoo.co.id \\ ${ }^{3)}$ sapty@mail.uajy.ac.id
}

Article history: $\quad$ Abstract

Received 30 May 2018

Revised 15 September 2018

Accepted 3 October 2018

Available online 28 October 2018

Keywords:

Small and Medium Enterprises Human Resource Management Information System

Technology
Small and Medium Enterprises (SMEs) in Indonesia continue to grow because it is supported by ideas and creations of the community that keep creating new idea either from food products, clothing, or multipurpose tools. There are already a few examples of successful IT implementation on SME in many countries, but in Indonesia, many SME's does not yet know about the benefit of IT implementation in their businesses. To solve this problem SME's need for learning and adapting IT from the internal functions of the organization, and one of them is Human Resource Management (HRM). This research will try to redesign HRM system based on mobile system or smartphones as one of most popular and most used technology in Indonesia. Smartphones can be used as an early and easy approach for those SME's in the IT-based system. This research will be focused on collecting qualitative data based on the interview with 5 respondents as owner or manager of SME to specify requirements of the design and problems that can be solved. As for the results, the major problem is from the human resource which is lack of knowledge, experience and there are few internal problems in SME's which can be solved by redesigning the mobile system. After presenting the result of redesigning, respondents conclude that the system is sufficient for their daily business activities and they feel comfortable with the design on the mobile system as they said it is easy to understand. Presented design can be much improved by adding more information, opinion, and feedback from other SMEs into consideration in the aim to achieve effective and efficient system design.

\section{INTRODUCTION}

Information systems have developed and spread to various levels of the organization, even to many forms of business management [1]. A company, for example, the large one should know its strength and weakness to make an effective strategy of resource in order to compete [2]. Large companies no longer dominating utilization of information technology as one of the success factors of a business unit. Many business units on the scale of Small Medium Enterprises (SMEs) are beginning to utilize information technology to support their business processes [3]. SMEs are not small players in the business world, and even in the trading market more and more small businesses are selling products that do not yet have a well-known brand to compete for profit in the business world [4]. However, ERP implementation studies of large companies point to many failures experienced both from the technical side, implementation [5], and the environment that always impacts an organization [6]. Thus, SMEs have a tough challenge to start implementing ERP in their business areas, especially on the limited resources, budget, and time needed for implementation and adjustment [7]. Looking at the many areas of the existing ERP, this study

${ }^{*}$ Corresponding author 
attempts to link information systems to one of the key internal areas of ERP that are important to SMEs, namely Human Resource Management (HRM) [8]. Good relationships between owners or managers and among employees are very important in making a comfortable work environment and developing an entrepreneurial behavior [9].

Human Resource Information System usage allows human resource (HR) in an organization to become a strategic player for the organization. In a study by Hussain et al. [10] as time goes, functionality and affordability for HRIS keep increasing and HRIS used in the organization of all sizes. Despite that, there is a possibility of disparities between large and small company. On author's research, the result achieved that there are few differences exist between SME and large company usage on HRIS. There is evidence that small companies like SMEs feel that the costs of implementing HRIS system are too high, but there is also evidence that for SME, there is an improving return of investment on HRIS system. There are already some researchers advocating the integration of human resource management functions with business strategic planning to maximize the value a business can generate from employee activities and cycles [11]. The HRM system in a small and medium-sized business is closely related to the point of view of the owner or leader about the relationships between employees. It is important to adopt an approach that generates high commitment from SMEs owners or leaders [12].

In a study by Suzanne et al. [13] in analyzing HRM activities at SMEs in Hungary through a questionnaire survey of a large sample of 678 Hungarian SMEs, the authors assessed HRM systems that have been used in some HRMs in Hungary and explored the relation of HRM activities performed with the size and performance of SMEs. The results found are that the majority of SMEs in Hungary have models that work together and even make the lack of skill aspect not a problem in their business processes. In terms of communication, the methods encountered are the majority of informal methods, but there is little reluctance to conduct future planning discussions between employees. There are internal and external factors that influence the adoption of HRM in a SMEs [14]. In Sheehan's research, [15]the authors conducted research on several SMEs by examining the relationship of human resource management in a longitudinal manner and resulted in the conclusion that the selected human resource management implementation had a positive aspect to SMEs performance. With the long-term nature of relationships, investing in human resources becomes the key to gaining huge profits in SMEs. However, SMEs owners should invest cautiously because investment in human resources can have a significant impact.

The area of HRM and productivity has become a living area and made great strides in the past 2 decades [16]. There arose the problem of how a small-scale SMEs can implement technology-based HRMs effectively and efficiently. But there is already some evidence that HRM strategies can be achieved by small business ventures[1719]. Keep in mind that the HRM approach to an organization differs from country to country, and even from one organization to another because it must adapt to the environment of the country or organization [20]. This research will be focused on collecting qualitative data based on the interview with 5 respondents as owner or manager of SME to specify requirements of the design and problems that can be solved. As for the results, the major problem is from the human resource which is lack of knowledge and experience and there are few internal problems in SME's which can be solved by redesigning the mobile system. Respondents for this research will be the owner or manager of SMEs in Tasikmalaya. Data collection will be using the interview method in some aspect to get appropriate qualitative data needed for this research. Topics included in the in-depth interviews start from the HRM implementation objectives for SMEs respondents, followed by HRM methods and methods that have been done up to now, and continued on issues and HRM constraints that have been experienced as well as the impact seen on the SMEs business process of respondents. Then the data will be analyzed and processed to determine the structure of the SMEs team [21] and make the category of problems encountered along with the frequency of the overall SMEs interviewed. Then proceed with the design of a mobile information system design to answer the problems encountered by SMEs.

\section{METHODS}

The flow of this research (Figure 1) will starts from the selection of samples and data acquisition which is then followed by qualitative data analysis obtained and used to design the appropriate HRM system design for SMEs in Tasikmalaya to be effective and convenient to use in their business processes. In the data analysis phase, this study will use the team structure framework [14]to determine the teams present in each sample SMEs, then the problems and constraints of the employees' management encountered will be grouped as important points that must be addressed by the design to be made in the stage of build mobile HRM system design. 


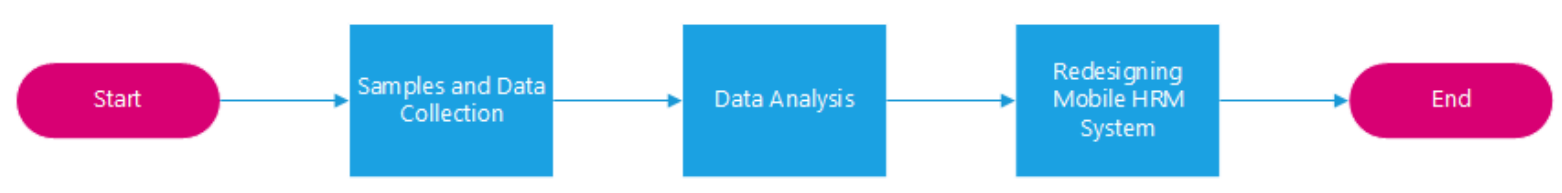

Figure 1. The Flow of Research Methodology

\section{A. Sample and Data Collection}

The data used for this study came from a random sample of available SMEs, but in the SMEs, the selection used 2 dimensions as a requirement of SMEs: 1) the main business sectors in the production of clothing and 2) independent ownership (i.e. not being part of other organizations). With only a small number of personnel available in SMEs locations in Tasikmalaya, the eligibility criteria are SMEs that have between 5 and 10 key employees (fixed with SMEs owners in one location) although more employees may be elsewhere (i.e., production houses or of the outsourcing contract). With a small primary employee size, research can be more focused on the problems and implementation of HR systems in administrative functions so that implementation is expected to follow SMEs business flow to adjust and avoid the risk of failure in the middle of implementation due to lack of SMEs knowledge and experience of information systems, especially the HRM system.

Data collection methods used are in-depth interview to explore employee activities and how HRM has been run by respondents as the owner of SMEs. Interactive questions will also focus on the owner's observation as the center of SMEs business process control of the causes of the problems encountered and what solutions are appropriate and feasible. After in-depth interviews, respondents will be given early design plans based on literature studies related to the design of information systems on mobile [22-24]. The aim of this step is to approach respondents and ask for respondent's opinion with the design (Figure 2) as an object to support respondent in giving opinion and feedback for the design of HRM mobile system. Remembering that respondents not yet have experience in implementing IT in their business, this way interview process can be more interactive and avoid a condition where respondents confused and giving non-legit qualitative data for this research. Features that available in this design are included as basic communication tools for the internal human resource in SMEs, and next step of redesigning process will follow qualitative data from respondents.
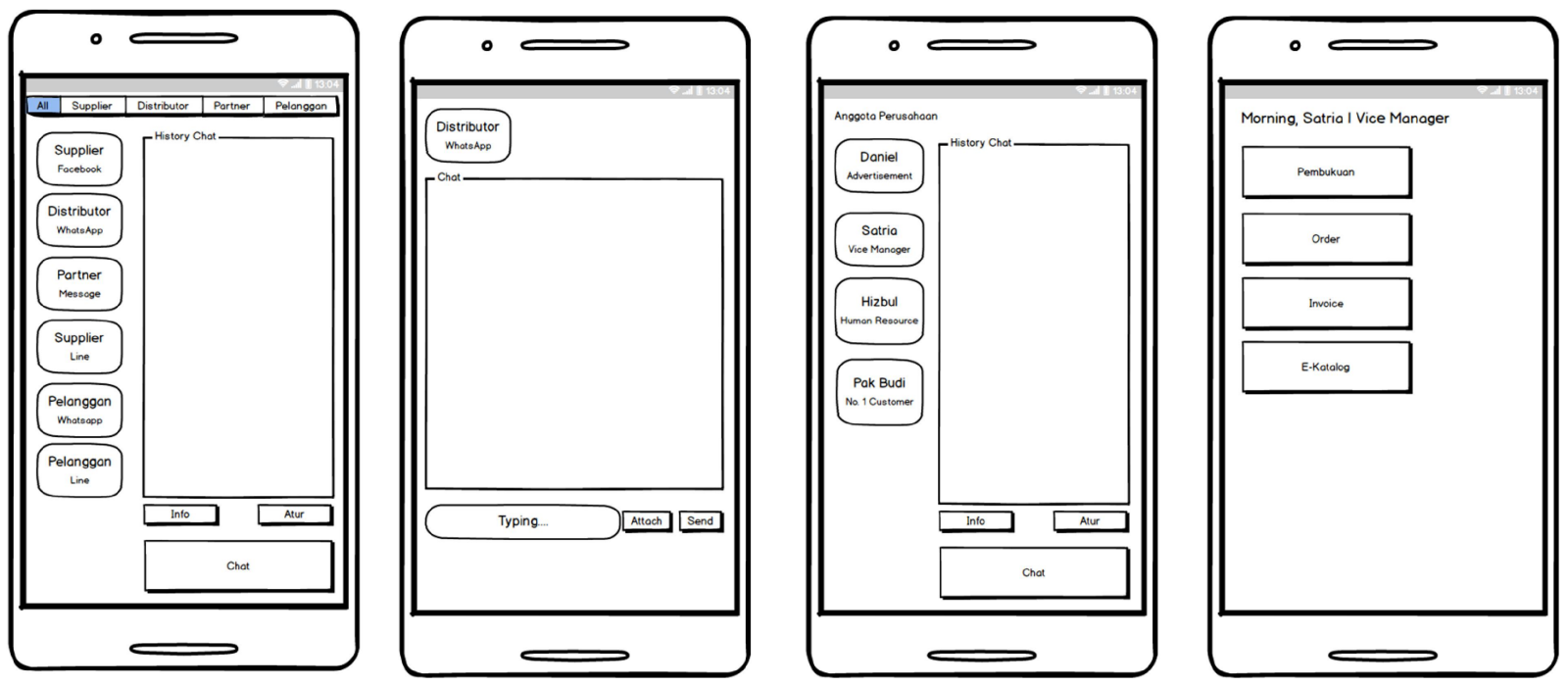

Figure 1. Design of Example view in Communication Activity

\section{B. Data Analysis}

Team structure of SMEs refers to the organization of the SMEs itself and the project team. A small company like SMEs, for example, has limited resource, personnel, and other aspects from financial or technical. Therefore, for SMEs team structure can be broken down into four categories [21]. Isolated Function, Lightweight, and A-Team are like a small difference between one and the other. These team structures are an organizational structure that requires fixed personnel on each task or function (e.g. marketing, finance, marketing, etc.) as well other aspects to maintain 
financial and technical resource to maintain SMEs. On the other side, heavyweight strategy team structure can be applied to SMEs without requiring the dedication of full-time members. The responsibility of each functioning participant can vary depending on what the project's goal and need.

TABLE 1

TEAM STRUCTURE CLASSIFICATION

\begin{tabular}{ll}
\hline \hline Team Structure Category & Description \\
\hline Isolated Function & Every individual in SMEs is responsible in their respective areas. \\
Lightweight & $\begin{array}{l}\text { Roles in SMEs are made into a stratosphere of the owner/manager, and the manager's project is responsible to } \\
\text { the manager. }\end{array}$ \\
Heavyweight & $\begin{array}{l}\text { SMEs owners/managers have full control over the overall SMEs team. In addition to managers, others are at the } \\
\text { employee level. }\end{array}$ \\
A-Team & Just like Heavyweight, but for cases where SMEs have implemented ERP \\
\hline \hline
\end{tabular}

The qualitative raw data from the in-depth interview phase will be analyzed and processed for 2 purposes: 1) Classification of SMEs team structure and 2) Classification of problems in SMEs related to employees and human resource management. The classification of the team structure adopted the framework of Malhotra et. al. and adapted to the characteristics of SMEs in Tasikmalaya that may still unfamiliar with the technology. The classification of the team structure and its description is shown in Table 1.

\section{Designing Mobile HRM System}

The design of the mobile HRM system design will be created using mock-up software as result from data analysis. Part of the mobile HRM system to be designed includes communication functions, employee management, and employee job management. These three functions are expected to help the owner to control his employees and manage employee resources for effective and efficient business processes with good and stable performance.

\section{RESULTS}

There are 5 SMEs for samples of this research and all of it have business process production of apparels. The respondents interviewed were the managers or owners of the related SMEs. The five SMEs have their respective problems in human resource management and the majority are due to the absence of systems that assist the process, all of which are still manual either from employee recording to recording the division of labor. These five SMEs take advantage of technology to their activities in the form of communication using smartphones, but which can be used only as SMS, Chats, or voice calls as is usually done in everyday life, but this will facilitate the process of adjusting the implementation of mobile HRM system for their SMEs.

SMEs $\mathrm{A}$ is one of the SMEs in Tasikmalaya who mainly in the business of clothes and convection lace. Respondents as owners of SMEs A have roles in administrative duties. Other employees are on duty in other areas like production processes or sewing at production sites. SMEs A prefers the good process of cooperation in discussion activities, decision making and even solving a problem that related to the SMEs business process. Some of the problems encountered by SMEs A in is the data recording and data store because it is resulting problems in the employees' management and the task assignment that sometimes do not sync and blocking each other.

SMEs B main area is fashion convection and transforms raw materials of clothing onto products or finished clothes. The owner focuses on controlling the whole business process and participating in the production like process making of clothes. For product marketing and other services, they did it by using employee from outside of SMEs (e.g. through advertising and outsourcing). The duties and responsibilities associated with one role are handled by the employee with that role, but for issues related to SMEs as a whole (e.g. policy changes or procurement cooperation), the discussion will be held with meetings and brainstorming with the entire internal employees. In SMEs B problems in human resource management are not so visible but the management of employees can be upgraded with a computerized system to be more optimal.

SMEs $C$ is engaged in the production of Muslim clothing (e.g. mukena). The production process has been running so far by utilizing outsourcing to outsiders for the manufacture of the product, which usually takes part of the total amount or entirely if there are too many incoming orders. The main problem is occurring in recording outsourcing data because it is still manual and has not been integrated with a system, and the result is SMEs C and outsiders have different data recording. Problems on internal employees can still be considered mild because although it has different roles and functions, employees in SMEs C sometimes work together so that problems can be resolved more quickly.

SMEs D is engaged in the production of home industry and still using traditional business process system. According to respondents of SMEs D, there are many problems and obstacles found in their business process due to 
the traditional way. Communication process of managers with employees in SMEs D is frequently problematic especially in decision making about a problem because sometimes there are employees who have not given an opinion or still not satisfied with decision resulted.

SMEs E is engaged in garments that produce Muslim fashion. The owner of this SMEs also doubles as the overall business control. In the production activities, owner outsourcing system to third parties in the production process from the start, cutting, suturing, pattern and the installation of the brand. For the management of resources especially in the task assignment SMEs E is quite effective for business processes but can be improved with the HRM system.

Overall, from all interview results, there are few aspects surfaced that constraints implementation of Human Resource Management System according to the owner of these SMEs. First of all is SME's lack of knowledge of IT system that prevents owner for a try or even planning to implement IT system into the business process. Secondly is organization behavior which is fond to traditional way of business. All functional members in the SMEs feel comfort do their responsibilities using without-risk traditional way rather than trying new system-based way with various risk included. Third, lack of capable and experienced member in implementing IT system on business process. Without a role model in an organization, it is hard for all members to learn and recognizing IT system for their business in a way to aim implementation of IT system in the future because it cannot be done in a short time.

\section{A. SMEs Team Structure}

Table 2 shows the characteristics of the structural team of each SMEs of 5 SMEs interviewed, and it can be seen that the majority of the SMEs team structure is Heavyweight which means that SMEs managers and owners have full control over SMEs. With these characteristics, the system created will give full access rights for the owner who can then manage the role and permissions of other employees in the administration or management of general employees in SMEs. The system should also have good reusability and comfortable considering the small smartphone screen but will be filled with the HRM employee resource management functions.

TABLE 2

SMES TASIKMALAYA TEAM STRUCTURE

\begin{tabular}{ll} 
& SMES TASIKMALAYA TEAM STRUCTURE \\
\hline \hline SMEs & TEAM STRUCTURE \\
\hline SMEs A & Isolated Function \\
SMEs B & Lightweight \\
SMEs C & Heavyweight. \\
SMEs D & Heavyweight \\
SMEs E & Heavyweight \\
\hline \hline
\end{tabular}

\section{B. SMEs problems in Human Resource Management}

Based on in-depth interviews conducted with the owners and managers of the five relevant SMEs, then obtained data on issues related to the management of human resources i.e. employees of SMEs. Table 3 shows the classification of the problem along with the percentage of the problem from a total of 5 SMEs respondents. Based on table 3 it can be seen that the great potential for mobile HRM system to help human resource management in the five SMEs. The five respondents expressed enthusiasm and wanted to try the system to be implemented in overcoming the emerging problems. On the chart (Figure 3) it can be seen that the highest problem is the initial design that is presented to the respondent, i.e. the need for a platform that can be designed for communication to discuss matters in SMEs either the upcoming planning discussion or the problems that occur in order to be quickly resolved.

TABLE 3

HRM PROBLEM IN SMES TASIKMALAYA

\begin{tabular}{ll}
\hline \hline HRM PROBLEM & Percentage \% (from 5 SMEs) \\
\hline Difficult doing task assignment & 60 \\
Employees data record not efficient & 80 \\
Messy employee's data record & 80 \\
Need of communication platform for discussing SMEs stuff & 100 \\
Pilling up task from upcoming production order & 60 \\
\hline \hline
\end{tabular}

\section{Redesigning Mobile HRM System}

According to interview result with 5 owners and manager of SMEs, first, these SMEs need an approach and easy step to start using IT system in their business process, also adding knowledge and experience as a requirement for the future complex system. Instead of forcing an implementation of full HRM functionality, it is decided to design an HRM system with just a few functions that important and possible to improving business process of these SMEs. Area of this system mainly helping organize employees because this system aiming to train and make all members 
of SMEs be at ease using IT system, avoiding nervousness and feel afraid to use more complex information system in the future.

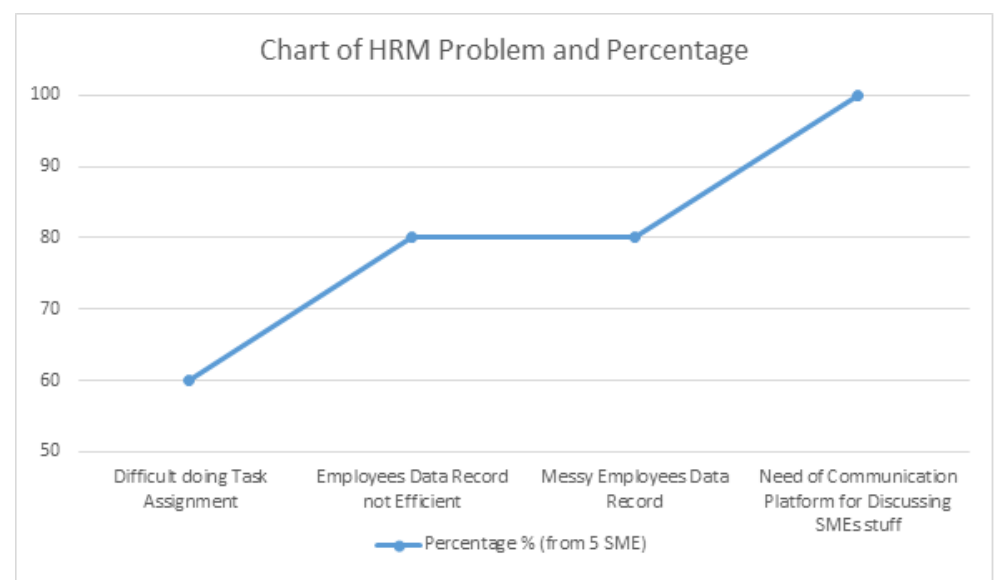

Figure 2. Chart of HRM Problem and Percentage in SMEs Tasikmalaya

\section{1) Communication/Chatting}

The interface (Figure 4) is a view for communication and chat between employees in SMEs. For example, the conversation is described talking to take the decision of recreation destination between beaches, mountain climbing, pool party, and going to Bali. However, this decision-making can also be used for the purposes of voting business activities in SMEs. Anyone can make the voting action and then everyone who is the other person is expected to vote and enter as shown in the picture on the right. The result of the vote will be listed in the chat and the number of votes is shown in the form of numbers so that all transparent and each person can directly give an opinion or other suggestions if not agree. This design is based on the problems encountered in SMEs B and D about ineffective communication and sometimes the decision fluctuates because there is no agreement with the decision taken.
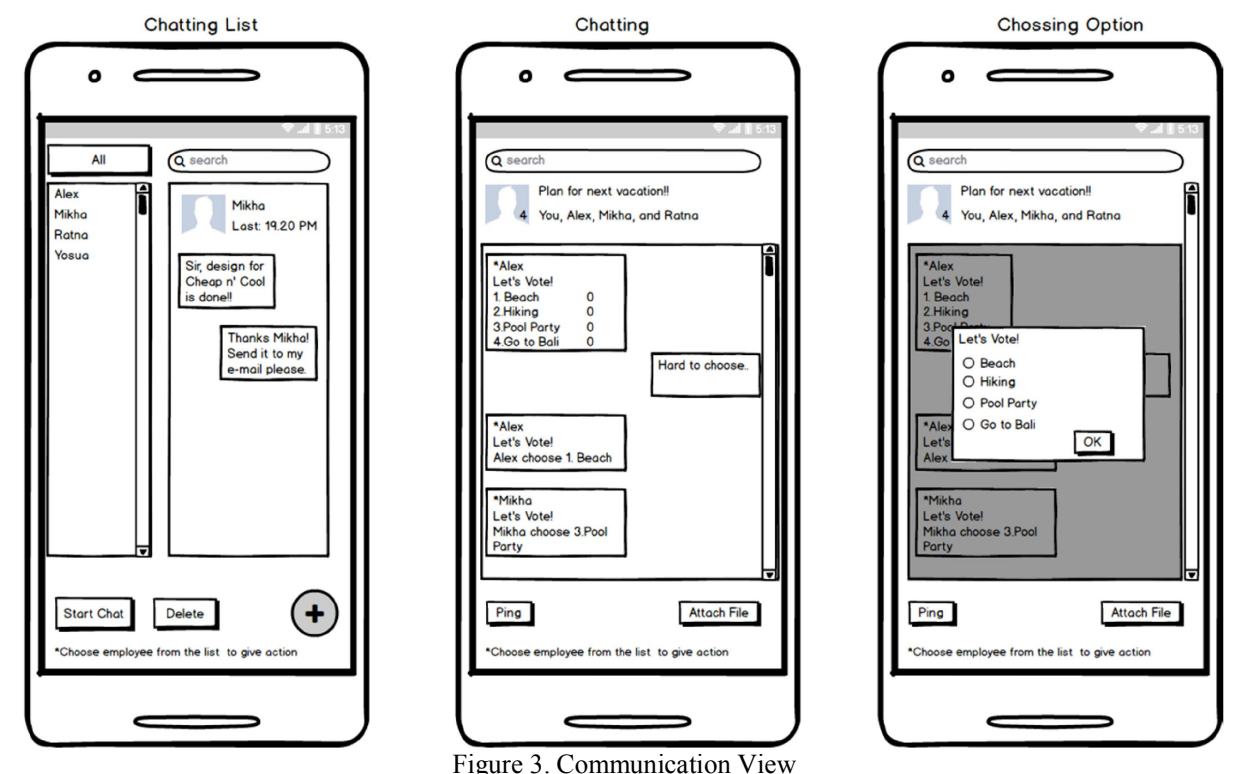

\section{2) Employees Management Function}

The interface (Figure 5) is a view for of management. Data that can be filled include name, gender, birth date, employee ability, address, contact no, and no hp. Word "Skill" here is meant the role of the employee in SMEs and specified by the owner when adding an employee to data. Employee skills can be more than one. In the task check section, the owner can see the tasks that are being performed by certain employees to stay in control and the task is 
completed on time. For status data is updated by the employee concerned as the info given to the owner regarding the progress or progress of the task given. This function is used to solve the problem on SMEs A and SMEs B.
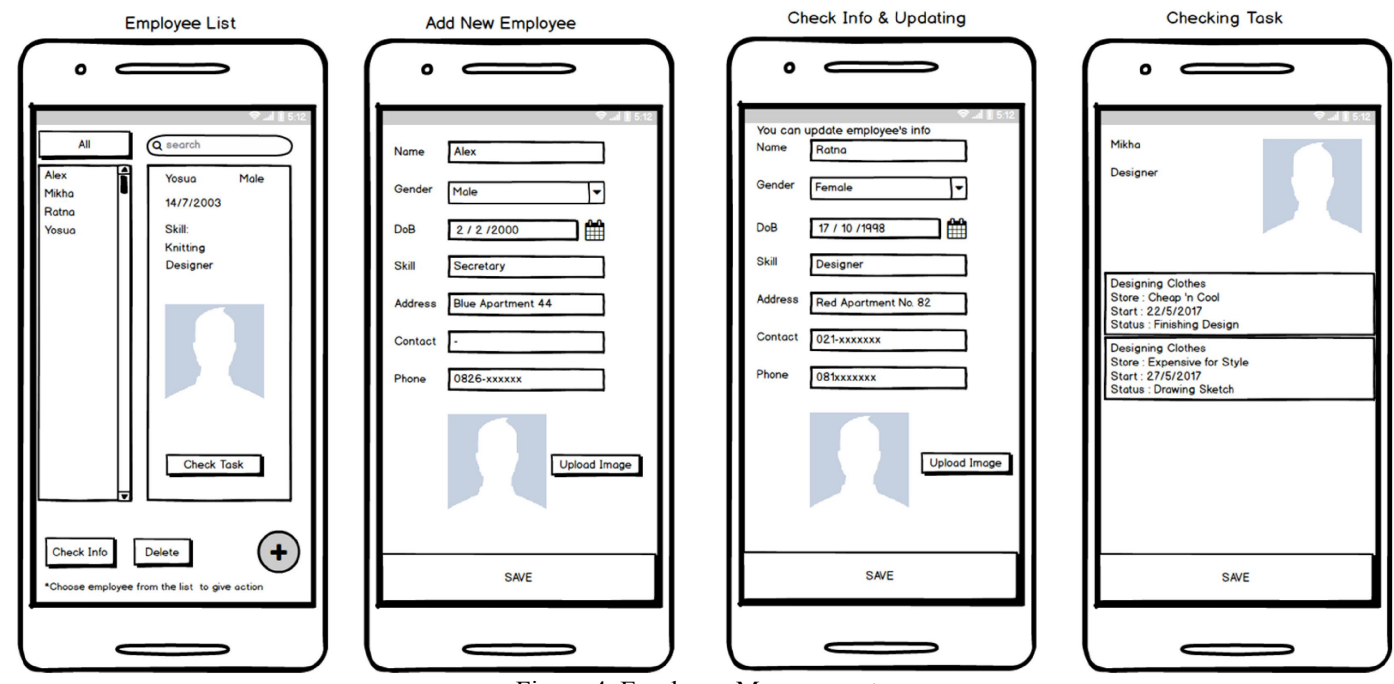

\section{3) Task Assignment}

The interface below is the view when the owner wants to assign tasks to employees by selecting employees and given the option to check in advance the tasks being in progress by these employees. After selecting the employee then, the owner can provide new tasks that can be given data in the form of the name of the buyer, and in this case study is usually the name of the shop that order. Then the job description and then the start date and deadline of the task. Here the task assignment function is just a data record to be synchronized and aligned among all employees of SMEs related. Progress work can also be monitored and controlled by the owner if there are tasks done slowly and threatening the transaction or order related products. This function is a solution to the problems experienced by SMEs D and SMEs E.
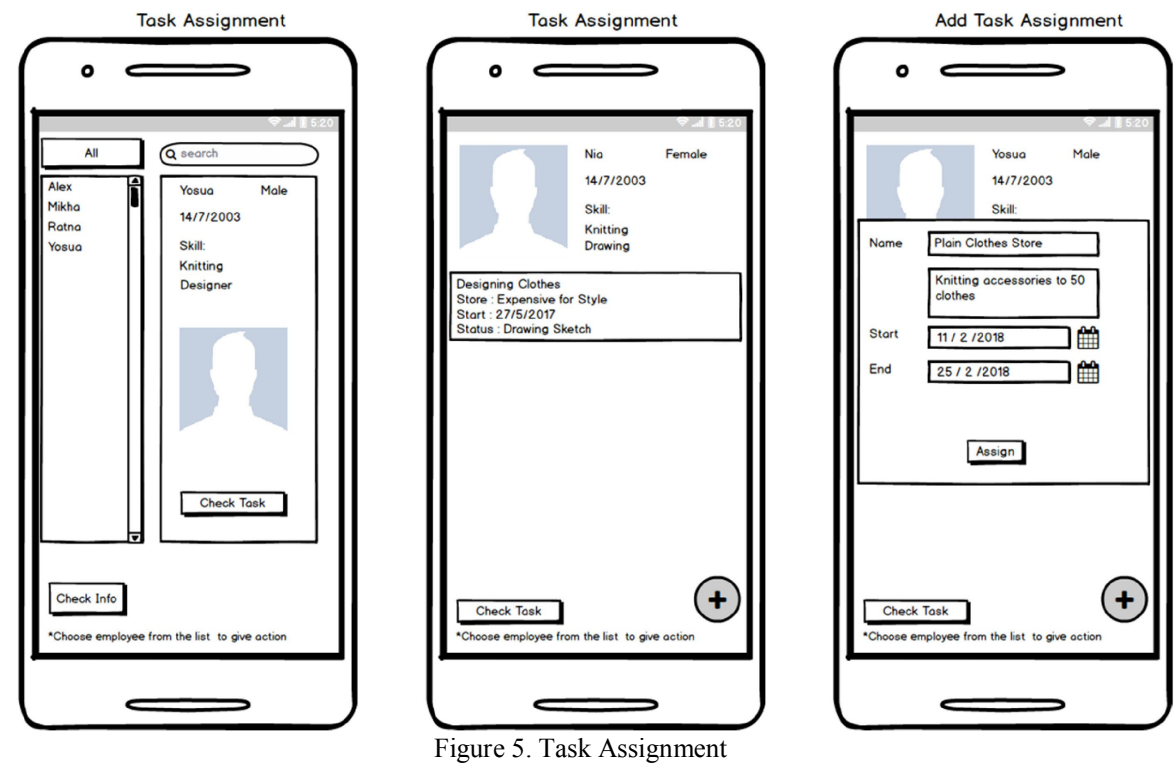

\section{Evaluation}

The result of redesigning is still lacking so much compared to existing mobile HRM system that has covered up all section on HRM process (e.g. JPayroll). But, the majority of widely used mobile HRM system available are 
assuming user have experienced in using a related system. Unlike a big company, these SMEs still have difficulty with straightforward implementing available mobile HRM system. Therefore, the main idea of this research is how to redesigning mobile HRM system and approach certain SMEs that lacking knowledge and experience in implementing IT on their business.

The result of our research including presented function and interface of the system (Fig. 4, Fig. 5, and Fig. 6) are the final result from repeat evaluation process including the interview and feedback collection with respondent. The evaluation process is using cases of an example of the business process that happened in their business and how the presented idea gives a new way of solving or avoid problems. Respondents conclude that the system is sufficient for their daily business activities and they feel comfortable with the design on the mobile system as they said it is easy to understand. The results of this research give a new idea and approach for redesigning mobile HRM system for SMEs that have low experience of IT system and lacking motivation for implementing IT in their business.

\section{DISCUSSION}

Overall, these five SMEs are running their business processes traditionally, especially on data recording which is one of the important factors in any business activity. The risk of losing data and vulnerable data storage media is a big problem in these five SMEs, but until now manual way is still used because there is no trial for the implementation of information systems to their SMEs even the widely used bookkeeping using Microsoft Excel has never been tried. But that does not mean the five SMEs are really blind to the technology and cannot implement. The results obtained thoroughly is that the five SMEs in Tasikmalaya already have basic knowledge of smartphone technology that arises because of daily use. With that knowledge, when in the process of interviewing for system design, respondents can give good suggestions in terms of function and good reusability and comfortable for them. The problem of communication platform becomes the most, with the percentage of $100 \%$ (5 of 5) because although there are many communication platforms like Short Message Service (SMS), WhatsApp or Facebook, respondents feel there is no match for communication purposes in SMEs which where there are special functions such as decision-making described chapter results.

Compared to previous studies on mobile HRM system, this research gives a new approach to SMEs in Indonesia, especially in Tasikmalaya. SMEs with lack of knowledge and experience in IT need a special way to approach, trying, and learning IT system for their business. One of the solutions is making a personalized system with interface and design that user-friendly for users doing tasks in the business process. There are few aspects in this research that can be improved to minimized threats to validity such as experimental variable in made basic design as objective to support the first interview for each respondent and maturation on each respondent after repeated interview for opinion and feedback on the improved design.

\section{CONCLUSIONS}

This study uses the adoption of team structure framework and problem classification on human resource management or HRM area in SMEs that become sample. The number of samples is fairly small only 5 SMEs, but it gives a benefit where the interview process can be focused on redesigning the system actively and interactive with respondents. In the future, the results of this research hoped can give a new idea and approach for redesigning mobile HRM system for SMEs that have low experience of IT system and lacking motivation for implementing IT in their business especially for SMEs in Indonesia. Also, the idea of personalized design on the mobile system for each categorized or classified SMEs (e.g. SMEs production in apparels area) expected to become more effective and efficient system to improve the business process for SMEs rather than the one-for-all design of mobile HRM system.

\section{REFERENCES}

[1] L. Raymond and S. Uwizeyemungu, "A profile of ERP adoption in manufacturing SMEs," Journal of Enterprise Information Management, vol. 20, no. 4, pp. 487-502, 2007.

[2] M. O. Riku and D. B. Setyohadi, "Strategic plan with enterprise architecture planning for applying information system at PT. Bestonindo Central Lestari," 2017 5th International Conference on Cyber and IT Service Management, CITSM 2017, 2017.

[3] H. E. Pramudiya, Y. D. Handarkho, and F. S. Rahayu, "Pengimplementasian CRM Pada Pembangunan E-Commerce untuk Usaha Mikro Kecil Menengah ( Studi Kasus : Dolanan Puzzle )," Buana Informatika, vol. 6, no. Oktober, pp. 257-268, 2015.

[4] A. Thomas, A. Hammer, G. Beibst, and T. F. Münte, "An ERP-study of brand and no-name products," BMC Neuroscience, vol. 14, 2013.

[5] M. Christofi, M. Nunes, G. Chao Peng, and A. Lin, "Towards ERP success in SMEs through business process review prior to implementation," Journal of Systems and Information Technology, vol. 15, no. 4, pp. 304-323, 2013.

[6] D. Budiyanto and D. B. Setyohadi, "Strategic information system plan for the implementation of information technology at Polytechnic 'API' Yogyakarta," 2017 5th International Conference on Cyber and IT Service Management, CITSM 2017, 2017.

[7] Y. Xie, C. James Allen, and M. Ali, "An integrated decision support system for ERP implementation in small and medium sized enterprises," Journal of Enterprise Information Management, vol. 27, no. 4, pp. 358-384, 2014. 
[8] M. Dabić, M. Ortiz-De-Urbina-Criado, and A. M. Romero-Martínez, "Human resource management in entrepreneurial firms: a literature review," International Journal of Manpower, vol. 32, no. 1, pp. 14-33, 2011.

[9] Á. Montoro-Sánchez and D. Ribeiro Soriano, "Human resource management and corporate entrepreneurship," International Journal of Manpower, vol. 32, no. 1, pp. 6-13, 2011.

[10] Z. Hussain, J. Wallace, and N. E. Cornelius, "The use and impact of human resource information systems on human resource management professionals," Information \& Management, vol. 44, no. 1, pp. 74-89, 2007.

[11] Eurostat, "Small and medium-sized enterprises (SMEs)," Eurostat, 2017.

[12] P. Black and D. Wiliam, "Inside the Black Box: Raising Standards Through Classroom Assessment," Phi Delta Kappan, vol. 80, no. 2, pp. 139-148, 1998.

[13] S. Richbell, L. Szerb, and Z. Vitai, "HRM in the Hungarian SME sector," Employee Relations, vol. 32, no. 3, pp. $262-280,2010$.

[14] N. Bacon and K. Hoque, "HRM in the SME sector: Valuable employees and coercive networks," International Journal of Human Resource Management, vol. 16, no. 11, pp. 1976-1999, 2005.

[15] M. Sheehan, "Human resource management and performance: Evidence from small and medium-sized firms," International Small Business Journal, vol. 32, no. 5, pp. 545-570, 2014.

[16] N. Bloom and J. Van Reenen, Human resource management and productivity. Elsevier B.V., 2011, pp. 1697-1767.

[17] S. Marlow and D. Patton, "Managing the Employment Relationship in the Smaller Firm: Possibilities for Human Resource Management.pdf," ed: International Small Business Journal, 1993.

[18] R. Barrett and S. Mayson, "Human resource management in growing small firms," Journal of Small Business and Enterprise Development, vol. 14, no. 2, pp. 307-320, 2007

[19] S. King-kauanui, S. U. D. Ngoc, and C. Ashley-cotleur, "Impact of Human Resource Management," vol. 11, no. 1, pp. 79-95, 2006 2006.

[20] N. Shah, "Predicting factors that affect students'academic performance by using data mining techniques," Pakistan Business Review, no. January, p. 631, 2011.

[21] R. Malhotra and C. Temponi, "Critical decisions for ERP integration: Small business issues," International Journal of Information Management, vol. 30, no. 1, pp. 28-37, 2010.

[22] M. A. Harris and K. P. Patten, "Mobile device security considerations for small- and medium-sized enterprise business mobility," Information Management \& Computer Security, vol. 22, no. 1, pp. 97-114, 2014.

[23] M. de Sá, "Designing and Evaluating Mobile Interaction: Challenges and Trends," Foundations and Trends ${ }^{\circledR}$ in Human-Computer Interaction, vol. 4, no. 3, pp. 175-243, 2011.

[24] B. J. Halpert, "Authentication interface evaluation and design for mobile devices," Proceedings of the 2nd annual conference on Information security curriculum development, pp. 112-117, 2005. 